\title{
Grid Service Operation
}

National Cancer Institute

\section{Source}

National Cancer Institute. Grid Service Operation. NCI Thesaurus. Code C64694.

An action, exposed through a Grid Service's interface, which requests some service-side processing to occur, optionally taking one or more inputs, and under normal processing, optionally returning one or more outputs. 